\title{
NOUVELLE
}

\section{Le récepteur \\ des phosphatidylsérines, une arlésienne qui nous surprend toujours}

Giovanna Chimini

> Dans le contexte de la mort par apoptose, une énigme qui est encore loin d'être résolue concerne les paramètres moléculaires et temporaux qui régissent l'élimination des « cadavres» (Figure 1), aspect souvent négligé mais fondamental car son déficit entraîne des répercussions importantes sur la réponse immunitaire [1]. En particulier, si une pléthore de signes moléculaires indiquant une mort cellulaire imminente ont été définis, ainsi que les caractéristiques des récepteurs impliqués dans la reconnaissance de ces cellules apoptotiques par les cellules phagocytaires, on sait très peu de choses des événements engageant les paires ligand-récepteur. La modification princeps liée à l'apoptose, l'exposition de phosphatidylsérines (PS) sur le feuillet externe de la membrane cellulaire, n'échappe pas à cette règle [1].

Depuis que les travaux pionniers de V. Fadok [2] ont révélé le rôle déclenchant des PS dans la phagocytose d'une cellule mourante, la

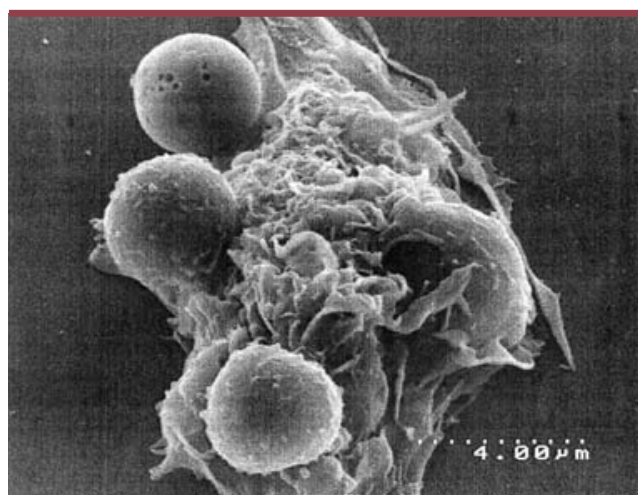

Figure 1. Un macrophage péritonéal de souris repère et engloutit des thymocytes en apoptose. Image en microscopie à balayage faite en collaboration avec Philippe Montcourrier, Université de Montpellier. menteux pour leur liaison à une cible), V. Fadok a abouti à l'identification d'une nouvelle protéine très conservée et qui mérite son appellation de récepteur de la PS (PSR) [3].

Si la conservation à travers l'évolution est rassurante, la séquence en ellemême est quelque peu surprenante. D'après les prédictions, il s'agirait d'une protéine transmembranaire de type II, par ailleurs dotée d'une séquence extracellulaire assez courte [3]. Peut-être quête du récepteur de ces lipides membranaires a commencé. Elle a été laborieuse car pendant longtemps toute nouvelle molécule candidate s'est révélé incapable de distinguer la PS d'autres lipides membranaires. Finalement, par une approche de biopanning (sélection d'un répertoire de molécules exprimées à la surface de phages fila- que cette particularité structurale soustend que la reconnaissance des PS fait intervenir un complexe multimoléculaire, responsable alors des difficultés d'identification du récepteur, voire du halo de mystère qui l'entoure toujours. rage morphologique ou biochimique sur
En particulier, nous n'avons aucun éclai-
Centre d'Immunologie

de Marseille Luminy,

Inserm/CNRS/Université

de la Méditerranée,

Parc scientifique de Luminy, case 906, 13288 Marseille

Cedex 09, France.

chimini@ciml.univ-mrs.fr

le fonctionnement du PSR au cours de l'enlèvement des cadavres de cellules apoptotiques. La nature moléculaire du récepteur est sans doute en cause car, outre sa faible immunogénicité, sa structure est peu propice à la génération d'outils substitutifs d'analyse, comme les chimères autofluorescentes.

Ce manque d'informations est devenu encore plus sensible depuis les analyses des phénotypes induits par l'absence du PSR chez C. elegans [4] et la souris [5, 6]. En effet, si les données confirment dans leur ensemble l'implication du PSR comme «avaleur» de cellules apoptotiques (l'engulfment anglophone), elles soulèvent d'autres questions.

Le PSR a été identifié chez le nématode, et l'analyse des mutants «perte de fonction» [4] montre un défaut d'élimination des cadavres, certes faible mais convaincant, parfaitement corrigé par la réintroduction du PSR homologue, partiellement si c'est l'orthologue humain qui est exprimé. À défaut de données morphologiques, l'analyse de double-mutants (PSR et ced) et les expériences de bypass positionnent clairement l'action de PSR en amont de l'un des deux circuits de contrôle de l'absorption des cadavres définis à ce jour. II s'agit de la voie ced2 , ced- 5 , ced-10 et ced-12 en opposition à celle définie par le groupe de gènes ced-1, ced- 6 et ced-7 [7]. Chez les mammifères, cette voie est typiquement déclenchée par l'engagement des intégrines et aboutit à la polymérisation de l'actine, et donc à la phagocytose, par 
activation de l'effecteur Racl [7]. On remarquera que, contrairement à l'inactivation des gènes en aval [7], celle du PSR n'entraîne aucun défaut de migration cellulaire ni aucun autre phénotype associé [4]. Cela suggère une spécifité fonctionnelle acquise par le PSR, qui contraste avec la promiscuité fonctionnelle des molécules effectrices en aval.

Le phénotype qu'induit chez la souris la délétion du gène codant pour le PSR est totalement différent et très radical, puisque les souriceaux meurent en période périnatale. Cela est exceptionnel dans les défauts «d'engloutissement» des cellules apoptotiques qui ont été caractérisés, d'autant plus que des malformations y sont associées. En effet M.O. Li et al. [5] décrivent d'évidentes anomalies du système nerveux central; bien que de pénétrance partielle, elles ressemblent à celles qui sont observées chez les animaux dont le déficit touche les molécules effectrices du processus apoptotique [8]. Dans la seconde étude décrivant les conséquences de l'invalidation du gène codant pour le PSR dans une autre souche de souris, des anomalies de l'hématopoïèse, touchant la thymopoïèse et l'érythropoïèse s'ajoutent au défaut d'《engloutissement» [6]. Malheureusement les deux études négligent l'observation du développement des membres, alors que nous le savons affecté dans plusieurs modèles animaux dans lesquels la formation de l'apoptosome, le processus d'«engloutissement» ou encore la différenciation macrophagique sont altérés [8-10].

Il faut remarquer à ce propos la discordance importante qui existe entre les deux équipes en ce qui concerne le recrutement des macrophages, important au niveau des lésions cérébrales [5] et apparemment absent au niveau du thymus ou du foie, lieu de l'érythropoïèse chez le fœtus [6]. Une analyse fine du renouvellement cellulaire (incluant à la fois le processus de mort et le processus d'«engloutissement») manque dans ces deux études; elle nous aurait peut-être aidé à comprendre les raisons sous-jacentes de ces différences. À titre explicatif, mais ce n'est qu'une hypothèse, on pourrait imaginer que le relargage des facteurs d'attraction des cellules phagocytaires varie selon le mécanisme de mort mis en œuvre.

Bien que les deux groupes utilisent des modèles de souris, dont le gène codant pour le PSR a été invalidé, qui ne sont pas strictement superposables et ciblent l'analyse de compartiments cellulaires différents, leurs données suggèrent que le PSR n'agit pas seulement comme une sentinelle dépistant les cadavres à éliminer, mais également comme molécule régulatrice de l'équilibre de mort cellulaire. L'ensemble des résultats associe en effet une réduction quantitative de la mort cellulaire au déficit de reconnaissance et/ou d'enlèvement via le PSR. Cette conclusion remet sur le devant de la scène une observation ancienne où l'absence de macrophages fossoyeurs entraînait l'absence de formation de la pupille (le développement de ce tissu est un bon exemple du processus de mort morphogénétique) [11]; elle corrobore également des résultats obtenus chez $C$. elegans et qui attribuent aux gènes de l'engulfment une fonction effectrice proapoptotique [12, 13]. Une question néanmoins se pose avec insistance: pourquoi seule l'inactivation du gène codant pour le PSR, alors que celle de différents gènes impliqués dans l'engulfment a été faite, révèle-t-elle ce rôle effecteur? Encore une fois, seul le décryptage des bases moléculaires du fonctionnement de ce récepteur pourra nous fournir quelques éléments de réponse. $\checkmark$

Phosphatidylserine receptor and clearance of apoptotic cells

\section{RÉFÉRENCES}

1. Savill J, Dransfield I, Gregory C, Haslett C. A blast from the past: clearance of apoptotic cells regulates immune responses. Nat Rev Immunol 2002; 2: 965-75.

2. Fadok VA, Savill JS, Haslett C, et al. Exposure of phosphatidylserine on the surface of apoptotic lymphocytes triggers specific recognition and removal by macrophages. J Immunol 1992; 148: 2207-16.

3. Fadok VA, Bratton DL, Rose DM, et al. A receptor for phosphatidylserine-specific clearance of apoptotic cells. Nature 2000; 405: 85-90.

4. Wang X, Wu YC, Fadok VA, et al. Cell corpse engulfment mediated by $C$. elegans phosphatidylserine receptor through CED-5 and CED-12. Science 2003; 302: 1563-6.

5. Li MO, Sarkisian MR, Mehal WZ, et al. Phosphatidylserine receptor is required for clearance of apoptotic cells. Science 2003; 302: 1560-3.

6. Kunisaki Y, Masuko S, Noda M, et al. Defective fetal liver erythropoiesis and T-lymphopoiesis in mice lacking phosphatidylserine receptor. Blood 2004; 8 janvier (online).

7. Alibert M, Chimini G. L'élimination des cellules apoptotiques: une phagocytose particulière. Med Sci (Paris) 2002; 18: 853-60.

8. Cecconi F, Alvarez-Bolado G, Meyer BI, et al. Apafl (CED-4 homolog) regulates programmed cell death in mammalian development. Cell 1998; 94: 727-37.

9. Hamon Y, Broccardo C, Chambenoit 0 , et al. $A B C 1$ promotes engulfment of apoptotic cells and transbilayer redistribution of phosphatidylserine. Nat Cell Biol 2000; 2: 399-406.

10. Wood W, Turmaine M, Weber R, et al. Mesenchymal cells engulf and clear apoptotic footplate cells in macrophageless PU.1 null mouse embryos. Development 2000; 127: 5245-52.

11. Lang RA, Bishop JM. Macrophages are required for cell death and tissue remodeling in the developing mouse eye. Cell 1993;74: 453-62.

12. Reddien PW, Cameron S, Horvitz HR. Phagocytosis promotes programmed cell death in C. elegans. Nature 2001; 412: 198-202.

13. Hoeppner DJ, Hengartner MO, Schnabel R. Engulfment genes cooperate with ced-3 to promote cell death in Caenorhabditis elegans. Nature 2001; 412: 202-6. 